DOI: $\underline{10.20472 / E S .2015 .4 .4 .003}$

\title{
EMPIRICAL ANALYSIS OF HERD BEHAVIOR IN BORSA ISTANBUL
}

\author{
HILAL HÜMEYRA ÖZSU
}

\begin{abstract}
:
Behavioral finance is a field that has grown toward the end of 20th century as a reaction to the efficient market hypothesis. This new field studies the effect of investor psychology on financial decisions and explains stock market anomalies in financial markets. Herding is such an anomaly that is defined as mimicking others' decisions or market trend.

The aim of the study is to detect whether there is herding or not in Borsa Istanbul. To test the existence of herding, stock returns traded on Borsa Istanbul and BIST 100 Index as market indicator are used. Data covers daily returns from 1988 to 2014 and intraday returns from 1995 to 2014. Firstly, herding is analyzed based on the methodology of cross-sectional dispersion of the stocks developed by Christie and Huang (1995) and Chang, Cheng and Khorana (2000). The results indicate that there is no herding for both up and down markets for daily and intraday intervals in Borsa Istanbul. However, tendency of herding is higher in up markets.

To enhance and compare the results, the methodology based on the cross-sectional volatility of beta coefficients suggested by Hwang and Salmon (2004) is used. This methodology has provided evidence of herding in Borsa Istanbul. It is also observed that investors follow the market trend more in session two markets rather than session one markets. Thus, it is concluded that investors imitate the others more under normal market conditions rather than noisy market conditions. These results are consistent with the assumptions of Hwang and Salmon (2004).
\end{abstract}

\section{Keywords:}

Behavioral Finance, Herd Behavior, Borsa Istanbul, Cross-Sectional Dispersion.

JEL Classification: G02, G14, C58

Authors:

HILAL HÜMEYRA ÖZSU, Gediz University, Turkey, Email: 35.hilal@gmail.com

\section{Citation:}

HILAL HÜMEYRA ÖZSU (2015). Empirical Analysis of Herd Behavior in Borsa Istanbul. International Journal of Economic Sciences, Vol. IV(4), pp. 27-52., 10.20472/ES.2015.4.4.003 


\section{Introduction}

Fama (1965) has developed efficient market hypothesis and argued that investors make decisions in a rational way to hold an optimal portfolio and maximize their returns at a given level of risk. Accordingly, market is efficient and investors have all available information which is reflected in prices. Thus, the market as a whole does not deviate from rationality. Contrary to this traditional approach to finance, behavioral finance states that investors are affected by their emotions during their judgment and decision making process under uncertainty and risk. Numerous researchers have emphasized the existence of unexpected results called as anomalies in financial markets, indicating market inefficiency during the past two decades.

Herd behavior is one of the anomalies which is defined in the finance literature as mimicking the other investors' decisions. The investors trade in the same directions with the other investors rather than acting based on their own beliefs. However, investors do not always follow the others to herd. They make similar decisions because of accessing the same information and interpreting this information similarly, which is called spurious herding. In case of intentional herding, investors should decide to follow the consensus after observing the others' behaviors. There are some forces leading to herd behavior such as information, reputation and compensation.

Researchers have analyzed herd behavior by using different measurement methods. The widely used methods are cross-sectional dispersion of stock returns, crosssectional volatility of beta coefficients and Lakonishok, Shleifer and Vishny (LSV) measure in the literature. In this study, firstly, the methodology of cross-sectional dispersion of the stock returns suggested by Christie and Huang (1995) and developed by Chang, Cheng and Khorana (2000) is applied. They have investigated whether dispersions of stock returns decrease during periods of large price movements. Small dispersions between stock returns and market return are expected during these periods if there is herd behavior. Then, the presence of herding is tested by using the methodology based on cross-sectional volatility of the beta coefficients. This model suggested by Hwang and Salmon (2004) provides to examine herd behavior under not only noisy market conditions but also normal market conditions. Moreover, the model enables to analyze herding by including macroeconomic fundamentals such as market volatility, market return, size and value factors. This also provides opportunity to differentiate intentional and spurious herding and to evaluate changes in herding levels.

This study, firstly, provides literature review and detailed explanation for the measurement methods of herd behavior. Then, the purpose of the study is covered, the data is described and the methodology is explained. At last, descriptive statistics and regression results are reported. The contribution and the suggestions for further research are provided in the conclusion part. 


\section{Literature review}

\section{Cross-sectional dispersion of stock returns}

Christie and Huang (1995) are the first researchers to develop and use the crosssectional standard deviations of stock returns. Christie and Huang (1995:32) state that investors mostly tend to act without disregard to their own beliefs, and thus, herding arises during periods of market stress. They have investigated whether dispersions of stock returns decrease during periods of large price movements in US stock markets. Large dispersions between stock returns and market return are not expected during these periods if there is a presence of herding. They have analyzed daily returns from July 1962 to December 1988, and monthly returns from December 1925 to December 1988. As a result of the analysis, their findings pointed out that dispersions of stock returns increase during periods of market stress implying that herd behavior has not been observed. Hwang and Salmon (2004: 587) argued that this may be due to investors basing their decisions on fundamentals rather than other investors' behavior at times of crisis.

Chang, Cheng and Khorana (2000) have extended the model developed by Christie and Huang (1995) and proposed the cross sectional absolute valuation of stock returns. They have investigated the herd behavior of investors in the United States (US), Hong Kong, Japan, South Korea and Taiwan by using daily stock returns. They have examined that not only decreasing but also non-linear relation is expected between dispersion of stock returns and market return to detect herd behavior. Their results indicate that dispersions of stock returns tend to increase implying that the returns do not herd around the market return during periods of large price movements in developed markets such as the United States (US), Hong Kong and Japan. On the contrary, smaller dispersions of stock returns have been found hence providing herd behavior in South Korea and Taiwan.

Many studies have attempted to investigate herd behavior by using the model developed by Christie and Huang (1995) and Chang, Cheng and Khorana (2000) in different international markets. Chen, Rui, and Xu (2003), Tan (2005), Demirer and Kutan (2006), Tan, Chiang, Mason and Nelling (2008), Chiang, Li and Tan (2010), and Liu (2012) have analyzed the existence of herding in Chinese Stock Markets.

Chen, Rui, and Xu (2003) have used the daily stock returns for the years 1996-2002 and have found no evidence on herding in either Shanghai or Shenzhen markets. With one exception that Shenzhen A shares and Shanghai B shares stand in contrast to the evidence of no herding in during extreme down markets.

Tan (2005) have examined the presence of herd behavior by using weekly data for both A and B shares listed on Shanghai and Shenzhen Stock Markets from 1995 to 2003 in his study. The regression results of weekly cross sectional absolute deviations indicated 
that herd behavior exists for both A markets. Additionally, while the stock returns don't deviate from the market return in up markets for Shanghai and Shenzhen A shares, the positive and statistically significant coefficients indicate the absence of herd behavior in all four down markets.

Demirer and Kutan (2006) have also examined the existence of herd behavior by using daily stock returns of individual firms from 1999 to 2002 and daily sector indexes from 1993 to 2001 to analyze the herding. They have found no evidence of herding in either Shanghai or Shenzhen Stock Markets, supporting evidence to the findings of Chen, Rui, and Xu (2003) and Tan (2005).

Tan, Chiang, Mason and Nelling (2008) have extended earlier studies of the Chinese Stock Markets and investigated the existence of the herd behavior by analyzing not only daily and weekly but also monthly stock prices for both A and B shares in Shanghai Stock Market and Shenzhen Stock Market over the period from 1994 to 2003. Herd behavior has been observed in all four markets when using daily data in both down and up markets. However, the results of weekly return observations have indicated the presence of herd behavior in Shanghai A-share and Shenzhen B-share markets. Similar to the weekly results, herding has been observed only in the Shanghai B-share market for monthly observations. The weaker evidence of herd behavior displayed in weekly and monthly data is consistent with the observation that "herd behavior is a very shortlived phenomenon" (Christie and Huang, 1995: 35).

Chiang, Li and Tan (2010) have studied the herd behavior of investors in both Shanghai and Shenzhen Stock Markets. They have stated that while the herding has been observed in both A-share markets, it has not been observed in either B-share markets. Nevertheless, regression analysis have indicated that while the herd behavior exists in down markets for both A-share and B-share investors, it has been observed only for Ashare investors in up markets.

Liu (2012) has used weekly stock data for A shares of Shanghai and Shenzhen Stock Markets for the years 2000-2009 to test the herd behavior. Liu has analyzed the dispersion of stock returns during both up and down market periods and found that investors do not herd in either down or up markets. As a deeper analysis, bubble and financial crisis periods between 2007 and 2008 have been investigated and no herding has been observed as well.

Lao and Singh (2011) have compared Chinese and Indian Stock Markets to examine the herd behavior on a daily and weekly basis by using cross sectional volatility of stock returns. The stock prices have been obtained from the Shanghai A-Share index, and the Bombay Stock Exchange index over the period 1999 to 2009. Although analysis of daily stock returns indicated strong evidence on herding in both the Chinese and the Indian Stock Markets, because of short-lived structure of herding, no evidence have been found when weekly data is used.

Gleason, Lee and Mathur (2003) have studied commodity futures traded on European 
exchanges, and Gleason, Mathur and Peterson (2004) have studied Exchange Traded Funds to measure the effects of herd behavior by using daily stock prices. Based on the methodology of cross sectional volatility of stock returns, the existence of herding has not been observed during periods of extreme market movements. Their results implied that the dispersion between stock prices and market return increases during periods of both down and up markets implying the absence of herding.

Al-Shboul (2012) and Henker, Henker \& Mitsios (2006) have examined the herd behavior based on the methodology suggested by Christie and Huang (1995) and Chang, Cheng and Khorana (2000) in Australian Stock Market. Daily and monthly returns have been used and large dispersions of stock returns have implied no evidence of herding during large price movements in the study of Al-Shboul (2012). However, small dispersions in up and down markets indicating that Australian investors herd.

Henker, Henker \& Mitsios (2006) have investigated market wide and sector herd behavior by using intraday and daily data. Except property trust sector, no impact of herd behavior has been observed on stock prices. The findings of property trust sector for both intraday and daily data indicate the existence of herd behavior in up and down markets.

The existence of herd behavior has also been tested on the Japanese Stock Market (Cajueiro and Tabak, 2009), on the Italian Stock Market (Caparrelli, D'Arcangelis and Cassuto, 2004), and on the Pakistani Stock Market (Javed, Zafar and Hafeez, 2013) by utilizing the method of cross-sectional volatility of daily stock returns. Cajueiro and Tabak (2009) have analyzed dispersions of stock prices on a daily basis. The findings are consistent with the existence of herd behavior in down markets. By contrast with the down markets, returns tend to diverge from the overall market return in up markets implying the absence of herding.

Caparrelli, D'Arcangelis and Cassuto (2004) have performed an analysis of daily stock returns from 1988 to 2001 in the Italian Stock Market. The regression results have indicated that dispersion of stock returns is higher and the probability of herding has been denied during the large price movements. Exceptionally, when they have analyzed the herd behavior during both extreme up and down market days, smaller stock return dispersions have been observed leading to a strong evidence on herding.

Javed, Zafar and Hafeez (2013) have investigated the existence of herd behavior by using monthly returns in Pakistan. No evidence of herding has been found during up and down market days consistent with the short-lived structure of herding.

Some of the researchers have carried out comparable studies on herding within different international markets. Economou, Kostakis and Philippas (2010) and Mobarek and Mollah (2013) have compared herd behaviors in four Mediterranean Stock Markets. Daily data obtained from Portugal, Italy, Greece and Spain (PIGS) has been analyzed by using the methodology of cross sectional volatility of stock returns. The findings of the study by Economou, Kostakis and Philippas (2010) indicate the presence of herd 
behavior only for Italian and Greek Stock Markets. There is an exception that during the global financial crisis, the dispersion has been observed in Portuguese Stock Market, as well, implying the existence of herd behavior. The results of the study by Mobarek and Mollah (2013) supported the existence of herd behavior during extreme market conditions, especially, during the global financial crisis and the Eurozone crisis.

Chiang and Zheng (2010) have utilized daily stock returns from 1988 to 2009 to investigate the herd behavior in developed, Asian and Latin American markets. Their sample covers the developed stock markets: Australia, France, Germany, Hong Kong, Japan, United Kingdom, and United States; Asian Markets: China, Indonesia, Malaysia, Singapore, South Korea, Thailand, and Taiwan; Latin American Markets: Argentina, Brazil, Chile, and Mexico. They have used the methodology of cross sectional volatility of stock returns proposed by Christie and Huang (1995) and Chang et. al. (2000). They have found herding effects on developed stock markets except the US and the Asian Markets in both up and down market days. The effects of herding have increased during the crisis periods. Exceptionally, in the United States and the Latin American Markets, herd behavior has been observed only during the crisis periods.

As similar with the study of Chiang and Zheng (2010), Zheng (2010) has investigated the effect of crisis on herd behavior during the periods of 1988-2009. The sample consists of advanced markets: Australia, France, Germany, United Kingdom, and United States; Latin American markets: Argentina, Brazil, Chile, and Mexico; Asian markets: China, Hong Kong, Japan, South Korea, Taiwan, Indonesia, Malaysia, Singapore, and Thailand. By using the cross-sectional standard deviations of stock returns, the findings of the study indicated that herding exists in each stock market except the US and the Latin American Markets for both up and down periods. The effect of herding increases during the crisis periods, consistent with the results of Chiang and Zheng (2010),

The study by Chiang, Li, Tan and Nelling (2011) have investigated the herd behavior in ten Pacific-Basin markets involving Australia, Hong Kong, Japan, Singapore, United States, China, Indonesia, Malaysia, South Korea, Thailand, and Taiwan. By using the data from 1997 to 2009, they have provided evidence on herding in both up and down markets based on the methodology of cross sectional absolute deviations of stock returns.

Altay (2008), Coban (2009), Kapusuzoglu (2011), Dogukanlı and Ergun (2011) and Kayalıdere (2012) have used different data sets obtained from Borsa Istanbul to test herd behavior. Altay (2008) has used sector classification to examine herd behavior during the periods of 1997 and 2008 in Borsa Istanbul. Daily data of services, financial, industrial and investment trusts sectors have been analyzed by utilizing the method of cross-sectional standard deviations of stock returns. To test the existence of herding, Altay (2008) has also implemented another methodology based on the cross sectional volatility of beta coefficients of the stocks suggested by Hwang and Salmon (2001, 2004). Herd behavior has been found towards the market portfolio. However, by 
contrast with the results of Christie and Huang (1995), the effect of herding decreases during the crisis periods.

Coban (2009) has obtained daily stock returns from Borsa Istanbul between 1997 and 2007 and used the cross sectional standard deviations of stock returns to test herd behavior. Regression results indicated that dispersion between stock returns and market return increases rather than decreases hence providing evidence of no herding in Borsa Istanbul.

Kapusuzoglu (2011) has investigated the existence of herd behavior by using daily stock returns obtained from BIST 100 Index. In contrast with the study of Coban (2009), the results of the study have supported the presence of herding over the periods from 2000 to 2010.

Dogukanlı and Ergun (2011) have analyzed monthly returns different from the previous studies in Turkey to examine the presence of herding. The data set, obtained from BIST All Shares, covers the periods of 2000-2010. Consistent with the Lao and Singh (2011) and Javed, Zafar and Hafeez (2013), the monthly returns diverge from the average market return hence providing no evidence of herding.

Kayalidere (2012) has used daily logarithmic stock returns between 1997 and 2012 in Borsa Istanbul and has divided the analysis period into two sub-periods, 1997-2004 and 2005-2012 to test the presence of herding. The findings indicated that there is herding during extreme up price movements, and there is no evidence of herding during extreme down price movements. At the second sub-period, between 2005 and 2012, the effect of herding has decreased and smaller effect has been observed.

\section{Cross-sectional volatility of beta coefficients}

To detect herd behavior, a more comprehensive model which based on the crosssectional volatility of the beta coefficients was developed by Hwang and Salmon (2004). The model based on the cross sectional volatility of stock returns is utilized for different periods within different stock markets to capture herd behavior. Wang (2008) has investigated herd behavior in 21 countries comparing the developed countries, the developing Latin American Markets and the developing Asian Markets. He has analyzed the size and book-to-market factors of the Fama-French three-factor model by monthly stock returns based on the methodology of cross-sectional volatility of stock returns from the period of 1985 to 2005. Consistent with the study of Hwang and Salmon (2004), it is observed that herding level in the developing Latin American and the developing Asian Markets is higher than the developed Markets.

Hassairi and Viviani (2011) has investigated herding by using Fama-French factors in European countries French, German, Italian and English stock markets are investigated as European markets with regard to herding. The method suggested by Hwang and Salmon (2004) is used. Herding is found in all countries, excluding periods of market turmoil and crisis. It is consistent with the assumptions of Hwang and Salmon (2004) 
which investors tend to herd more under normal market conditions rather than risky market conditions.

Pop (2012) has conducted his study in Romania to test the existence of herd behavior. $\mathrm{He}$ has measured beta herding by using the weekly excess returns covering the period from 2003 to 2012. Market volatility and macroeconomic factors have been used. He has concluded that herding level decreases during the market stress days such as crisis periods.

Messis, Zapranis and Kollias (2014) have analyzed the existence of herd behavior towards the market portfolio based on the CAPM approach. As similar with the study of Pop (2012), they have used macroeconomic variables such as gross domestic product (GDP), inflation, industrial production and 10Y Bond rate to detect herding. After they have found herding among investors, to test the contagion of herding, they have conducted the analysis to Germany, France, UK, US and China. The data covers the monthly returns from January 2000 to August 2011. As a result, herd behavior and contagion among countries are supported.

Gavriilidis, Kallinterakis, and Micciullo (2007) have studied the presence of herd behavior both during and after the Argentine financial crisis. They have obtained daily closing prices from Argentina's main market index (MERVAL) between 2000 and 2006 and analyzed herd behavior based on the cross sectional volatility of beta coefficients which is developed by Hwang and Salmon (2004). Both during and after the financial crisis, their findings showed smaller cross-sectional dispersion of the stocks' betas in Argentina stock market implying the existence of herd behavior.

Demirer, Kutan and Chen (2010) have investigated the presence of herd behavior in the Taiwanese stock market. Two different methodologies are compared to test herding over the January 1995 and December 2006 period by using a daily data set. While the first methodology suggested by Christie and Huang (1995) and Chang et al. (2000) indicates no evidence of herding, the methodology suggested by Hwang and Salmon (2004) indicates strong evidence of herding in the Taiwanese Market.

Seetharam and Britten (2013) have examined herd behavior between the periods of 1995 and 2011 in South Africa. Both the methodology of the cross-sectional dispersions of the stock returns and cross-sectional volatility of beta coefficients have been used to test the existence of herding. The results of these two methodologies indicate that while investors mimick the others during the periods of down market movement days, they do not follow the market trend during up market movement days.

As mentioned earlier, Altay (2008) has used cross-sectional dispersions of stock returns to test herd behavior by using daily stock returns between the periods of 1997 and 2008 in Borsa Istanbul within services, financial, industrial and investment trusts sectors. He has found herding among investors for the whole market. To compare the results, he has implemented another methodology based on the cross sectional volatility of beta coefficients of the stocks. Accordingly, investors tend to herd for the whole market 
except the periods of December 2003-April 2004 and May-October 2006 during extreme up and down price movements.

\section{Aim of the study}

The main purpose of this study is to measure the existence of herd behavior in Borsa Istanbul. This analysis aims to find out whether there is herd behavior or not in up and down market movement days and discuss herd behavior within session one and session two markets. This study also provides to capture herding by taking into account several factors such as market volatility, market return, size and book-to-market ratio.

This study is the first comprehensive attempt to measure herding in terms of market volatility, market return, size and book-to-market ratio factors in Borsa Istanbul. Furthermore, this is the first study that covers such an extensive period (1988-2014) and compares daily and intraday stock returns to evaluate herd behavior in Borsa Istanbul.

This study also contributes to the international literature in the field of behavioral finance by measuring similar variables that were used in the earlier studies and strengthening their theoretical and empirical frameworks.

\section{Data}

The research population is composed of stocks traded on Borsa Istanbul. Their daily closing prices were requested between the periods from $14^{\text {th }}$ January 1988 to $31^{\text {st }}$ December 2014. Daily closing prices of BIST 100 index were selected as the market indicator and were obtained from the official website of Borsa Istanbul from 1988 to 2014. The data also enables to analyze and compare intraday closing prices starting from $2^{\text {nd }}$ January 1995. There are 6417 daily observations and 9559 intraday observations in Borsa Istanbul for the study period. There were 47 stocks at the beginning of 1988 and 441 stocks at the end of 2014.

Daily and intraday closing prices were converted to daily and intraday logarithmic returns to calculate the dispersions. The following formula was used to calculate returns:

$$
R_{i, t}=\ln \left(P_{i, t} / P_{i, t-1}\right)
$$

where $R_{i, t}$ is the return of stock $i$ at time $t, P_{i, t}$ is the closing price of stock $i$ at time $t$, and $P_{i, t-1}$ is the closing price of stock $i$ on the day before.

\section{Methodology}

As mentioned earlier, cross-sectional dispersion of stock returns suggested by Christie and Huang (1995) and developed by Chang et al. (2000) and cross-sectional volatility of beta coefficients suggested by Hwang and Salmon (2004) are used to test the presence of herd behavior among investors in Borsa Istanbul. 


\section{Methodology of cross-sectional dispersion of stock returns}

This methodology measures the volatility of stock returns around overall market return. Dispersions between stock returns and market return are expected to be small during up and down market movement days in the presence of herding (Christie and Huang, 1995; Chang et al., 2000).

Cross-sectional standard deviation is calculated by using the stock returns to measure dispersion of the stocks:

$$
\operatorname{CSSD}_{t}=\sqrt{\frac{\sum_{t=1}^{N}\left(R_{i, t}-R_{m, t}\right)^{2}}{N-1}}
$$

where CSSD is the cross-sectional standard deviation of stock returns, $N$ is the number of firms in the portfolio, $R_{i, t}$ is the observed stock return of firm $i$ at time $t, R_{m}$, is the crosssectional average of $N$ returns in the portfolio at time $t$. To examine up and down market movement days, two dummy variables are taken into account and used in the following regression equation.

$$
C S S D_{t}=a+\beta^{D} D^{D_{t}}+\beta^{U} D^{U_{t}}+\epsilon_{t}
$$

where $D_{t}{ }_{t}$ is equal to one if the BIST 100 index return on day $t$ lies below the $1 \%$ and $5 \%$ of the return distribution and equal to zero otherwise, $D_{t}{ }_{t}$ is equal to one if the BIST 100 index return on day $t$ lies above the $1 \%$ and $5 \%$ of the return distribution and equal to zero otherwise.

Negative and statistically significant coefficient of $\beta^{D}$ and $\beta^{U}$ are indicators of small dispersions between stock returns and BIST 100 index return. It can be said that in this case stock returns do not diverge from the overall market return. Thus, it can be concluded that there is herd behavior during up and down market movement days in Borsa Istanbul. Moreover, Christie and Huang (1995) state that even if herding is not found for up and down markets, lower coefficient indicates that stock returns diverge from the market index less and hence investors tend to herd.

The same CSSD model is also conducted to measure the existence of herd behavior during up and down market movements in session one and session two markets rather than overall market. If coefficients of $\beta^{D}$ and $\beta^{U}$ are negative and statistically significant, there is herd behavior for both up and down market movement days in session one and session two markets.

An extended methodology based on the cross-sectional absolute valuation of the stocks developed by Chang, Cheng and Khorana (2000) is also used to test herd behavior. This model measures whether the relation between stock dispersions and market return is linear or not. Non-linearity is expected in the presence of herding.

Firstly, cross-sectional absolute valuation is expressed as: 


$$
\operatorname{CSAD}_{t}=\frac{\sum_{t=1}^{N}\left|R_{i, t}-R_{m, t}\right|}{N}
$$

where CSAD is the cross-sectional absolute deviation of stock returns, $N$ is the numbers of firms in the portfolio, $R_{i, t}$ is the observed stock return of firm $i$ at time $t, R_{m, t}$ is the crosssectional average of $N$ returns in the portfolio at time $t$, as mentioned in the previous chapter.

A quadratic equation is used to investigate the presence of herd behavior by using the following formula.

$$
\operatorname{CSAD}_{t}=a+\gamma_{1}\left|R_{m, t}\right|+\gamma_{2}\left(R_{m, t}\right)^{2}
$$

where $R_{m, t}$ is the average market return of the sample, at time $t$. The negative and statistically significant $\gamma_{2}$ coefficient indicates non-linearity hence resulting herd behavior. Thus, it can be concluded that there is herd behavior if there is non-linearity between market return and stock dispersion in Borsa Istanbul.

Following Chang, Cheng and Khorana (2000), a comprehensive regression analysis is conducted to capture the linearity between stock dispersions and market return in up and down market movement days in Borsa Istanbul.

$$
\begin{gathered}
C S A D_{t} D O W N=a+\gamma_{1} D O W N\left|R_{m t} D O W N\right|+\gamma_{2} D O W N\left(R_{m t} D O W N\right)^{2}+\epsilon_{t} \\
\text { CSAD }_{t} U P=a+\gamma_{1} U P\left|R_{m t} U P\right|+\gamma_{2}{ }^{U P}\left(R_{m t} U P\right)^{2}+\epsilon_{t}
\end{gathered}
$$

where $C S A D$ is the average cross-sectional absolute deviation of stock returns from the overall market return, $/ R_{m t}{ }^{D O W N} /$ is the absolute value of the average realized return of all available stocks during down market days, at time $t$ and $/ R_{m t} U P /$ is the absolute value of the average realized return of all available stocks during up market days, at time $t$. $\left(R_{m t}{ }^{D O W N}\right)^{2}$ and $\left(R_{m t} U P\right)^{2}$ is the squares of the identical returns in down and up markets. By using the equation, non-linear relation is expected between dispersion of stock returns and market return to detect herd behavior. The negative sign and statistically significant of $\gamma_{2}$ coefficient indicates a non-linear relation between CSAD and market return. It suggests that CSAD increases at a decreasing rate when the average market return increases hence providing evidence in favor of herding. Thus, it can be concluded that there is herd behavior if there is non-linearity between stock dispersions and market return in up and down market movement days. Additionally, positive coefficient of $\gamma_{1}$ indicates that CSAD increases with the size of market. Thus, when CSAD increases more in up markets, investors tend to herd less, and vice versa.

\section{Methodology of cross-sectional volatility of beta coefficients}

Following Hwang and Salmon (2004), the methodology based on the cross-sectional volatility of beta coefficients was employed to investigate herd behavior in Borsa Istanbul. This method measures the variability of the betas rather than stock returns. 
To be used in the analysis of cross-sectional standard deviation, beta coefficients were calculated by the following formula:

$$
E_{t}\left(r_{i t}\right)=\beta_{i m t} E_{t}\left(r_{m t}\right)
$$

where $r_{i t}$ is the excess return on asset $i$ at time $t, r_{m t}$ is the excess return on the market at time $t, \beta_{i m t}$ is the systematic risk measure, and $E_{t}$ is conditional expectation at time $t$.

Daily returns and risk-free rate (rf) were used to calculate the excess returns on asset $i$ and the market at time $t\left(r_{t}-r_{f}\right)$. As the risk-free rate, starting from the 1990s, yearly compounded interest rates of treasury discounted auctions were obtained from the official website of Undersecretariat of Treasury (www.treasury.gov.tr) and converted to daily rates $^{1}$.

To obtain the cross-sectional standard deviation of the beta coefficients on the market portfolio, the following equation was used as in Hwang and Salmon (2004):

$$
\operatorname{Std}_{c}\left(\beta_{i m t}^{b}\right)=\sqrt{\frac{\sum_{i=1}^{N_{t}}\left(\beta_{i m t}^{b}-\overline{\beta_{i m t}^{b}}\right)^{2}}{N_{t}}}
$$

where $\overline{\beta_{i m t}^{b}}=\frac{1}{N_{t}} \sum_{i=1}^{N_{t}} \beta_{i m t}^{b}$ and $N_{t}$ is the number of stocks in month $t$. To examine herding level over time, firstly, logarithms of the equation were taken as $\log S t d_{c}\left(\beta_{i m t}^{b}\right)$ and then the following regression equation is analyzed:

$$
\begin{gathered}
\log \left[\operatorname{Std}_{c}\left(\beta_{i m t}^{b}\right)\right]=\mu_{m}+H_{m t}+v_{m t} \\
H_{m t}=\emptyset_{m} H_{m t-1}+\eta_{m t}
\end{gathered}
$$

where $\eta_{m t} \sim i i d\left(0, \sigma_{m \eta}^{2}\right)$.

The equation of $\log \left[S t d_{c}\left(\beta_{i m t}^{b}\right)\right]$ is the measurement equation and the equation of $H_{m t}$ is the transition equation of the standard state space model. To extract $H_{m t}$, the standard state space model was applied by using Kalman Filter, as in Hwang and Salmon (2004). A significant $H_{m t}$ is expected in the existence of herding. The magnitude of $H_{m t}$ indicates the degree of herding. For instance, if $H_{m t}=1$, there is perfect herding.

To test the robustness of herd behavior in Borsa Istanbul, market volatility, market return, size and book-to-market factors were added to the model. If insignificant $H_{m t}$ is found when these variables are included, changes in the $S t d_{c}\left(\beta_{i m t}^{b}\right)$ can be explained

\footnotetext{
${ }^{1}$ Daily interest rates are calculated by dividing yearly interest rates to number of months in one year, number of weeks in one month and then, number of days in one week, as in Altay (2008).
} 
by changes in these factors rather than herd behavior (Hwang and Salmon, 2004). Then, herding found in Borsa Istanbul is evaluated as spurious herding.

Market volatility and market return were taken into consideration as independent variables as in Hwang and Salmon (2004) in the following estimation equation:

$$
\begin{gathered}
\log \left[\operatorname{Std}_{c}\left(\beta_{i m t}^{b}\right)\right]=\mu_{m}+H_{m t}+c_{m 1} \log \sigma_{m t}+c_{m 2} r_{m t}+v_{m t} \\
H_{m t}=\emptyset_{m} H_{m t-1}+\eta_{m t}
\end{gathered}
$$

where $\log \sigma_{m t}$ is market log-volatility and $r_{m t}$ is market return at time $t$. BIST 100 index daily returns are used as an indicator of market return between the periods of 1990 and 2014. To calculate market volatility values $\left(\sigma_{m t}\right)$, squared daily returns were used as in Schwert (1989):

$$
\sigma_{m t}^{2}=\sum_{i=1}^{N_{t}}\left(r_{i t}-\overline{r_{t}}\right)^{2}
$$

where $\bar{r}_{t}$ is the sample mean of the daily market returns and $r_{i t}$ is the daily market returns in month $t$, respectively. $N_{t}$ is the number of daily returns in month $t$.

If $H_{m t}$ is still significant when the market volatility and market return added, then, it can be concluded that there is an intentional herding rather than spurious herding in Borsa Istanbul. Thus, investors move in the same direction independent from the market volatility and market return. Moreover, negative and significant coefficients of log $\sigma_{m t}$ and $r_{m t}$ are indicators of non-linearity between the market variables and herd behavior.

Following Hwang and Salmon (2004), the size (small minus big, SMB) and book-tomarket (high minus low, HML) factors of Fama and French (1993) were also added to the model as independent variables and the following model is then written:

$$
\begin{gathered}
\log \left[\operatorname{Std}_{c}\left(\beta_{i m t}^{b}\right)\right]=\mu_{m}+H_{m t}+c_{m 1} \log \sigma_{m t}+c_{m 2} r_{m t}+c_{m 3} S M B_{t}+c_{m 4} H M L_{t}+v_{m t} \\
H_{m t}=\emptyset_{m} H_{m t-1}+\eta_{m t}
\end{gathered}
$$

where $\log \sigma_{m t}$ is market log-volatility and $r_{m t}$ is market return, $S M B_{t}$ is size (smallminus-big) factor and $H M L_{t}$ is book-to-market (high-minus-low) factor at time $t$.

To obtain size (small-minus-big) and book-to-market (high-minus-low) factors, 6 sizeBE/ME (book-to-market) portfolios based on the stocks were formed, following Fama and French (1993). Firstly, to calculate small-minus-big values, in June of each year $t$ from 1995 to 2014, all stocks have been ranked based on their sizes which were requested from Borsa Istanbul. By using the median value of these size values, they were divided into two groups as small and big. For high-minus-low values, book-tomarket values were also obtained from the official website of Borsa Istanbul. In 
December of each year t-1 from 1995 to 2014, book-to-market values have been ranked and divided into three groups They are broken as bottom (30\%), middle (40\%) and top $(30 \%)$ for the sample stocks. The stocks with the negative book values were not used as in Fama and French (1993).

It is expected that $H_{m t}$ is significant in the presence of herding. If the significance of $H_{m t}$ does not change when the size and book-to-market factors are included in the model, it can be said that there is an intentional herding rather than spurious herding in Borsa Istanbul. Thus, investors follow the market trend independent from the changes of size and book-to-market values. Moreover, negative and significant coefficients of $S M B_{t}$ and $H M L_{t}$ are indicators of non-linearity between Fama-French factors and herd behavior.

\section{Empirical Findings}

\section{Regression results for cross-sectional dispersion of stock returns}

Following Christie and Huang (1995), regression analysis was used to examine herd behavior during up and down market movement days. Table 1 provides the daily and intraday regression results for the equation of $C S S D_{t}=a+\beta^{D} D^{D_{t}}+\beta^{U} D^{U}+\epsilon_{t}$. The coefficients of the dummy variables capture the extent of herd behavior during periods with extreme up and down market movements. The $1 \%$ and $5 \%$ of the lower and upper tail of the market return distribution were used to identify days with extreme market movements.

As shown on Table 1, consistent with the study of Christie and Huang (1995), positive and statistically significant coefficients of $\beta^{D}$ and $\beta^{U}$ indicate that the stock returns do not herd around the market return during either down or up market movement days under the $1 \%$ criterion. The coefficients of $\beta^{D}$ and $\beta^{U}$ are also positive but insignificant under the $5 \%$ criterion indicating that CSSD do not diverge from the overall market, consistent with the absence of herding. In the presence of herding, negative and statistically significant coefficients of $\beta^{D}$ and $\beta^{U}$ are expected, as mentioned earlier. Thus, it can be said that there is no herd behavior during up market movement days and down market movement days. However, the estimates for $\beta^{D}$ are greater than $\beta^{U}$ under both $1 \%$ and $5 \%$ criteria indicating that the rate of dispersion is higher in the down markets than up markets. Thus, since stock returns diverge from the overall market return more in down markets, it may suggest that the tendency of herd behavior is higher in up market, even though there is no evidence of herd behavior. In addition, the $\alpha$ term represents the average level of stock dispersions when the market return is zero. The values of $\alpha$ are positive and statistically significant for both $1 \%$ and $5 \%$ of the return distributions. While $\mathrm{F}$ value is significant at $1 \%$, insignificant at $5 \%$ statistical level. This shows the validity of the model at $1 \%$ statistical level.

In line with the study of Christie and Huang (1995), positive coefficients of $\beta^{D}$ and $B^{U}$ are found indicating of no herding in Borsa Istanbul during extreme up and down market movement days for session one market. Negative and statistically significant 
coefficients are expected in the presence of herding. In other words, cross-sectional standard deviation is expected to be small between stock returns and the market return. Thus, it cannot be said that there is herd behavior during up markets and down markets based on these findings. The average level of equity dispersions is 0.1259 under $1 \%$, and 0.1242 under $5 \%$ criterion when the market return is zero. The cross-sectional standard deviation can be explained at a higher degree under $5 \%$ criterion than $1 \%$ criterion for market session one. $F$ value is significant to show the validity of the model for session one market.

Table 1 Regression results for cross-sectional standard deviation of the stock returns

\begin{tabular}{|c|c|c|c|c|c|c|c|}
\hline & & $a$ & $\beta^{\mathrm{D}}$ & $\beta^{U}$ & $\mathrm{~F}$ & $\mathrm{R}^{2}$ & Adjusted $\mathrm{R}^{2}$ \\
\hline & $1 \%$ criterion & $0,114^{\star *}$ & $0,046^{\star \star}(0,769)$ & $0,027^{\star}(1,792)$ & $6,364^{*}$ & 0,0020 & 0,0017 \\
\hline \multicolumn{8}{|l|}{ Daily Results } \\
\hline & $5 \%$ criterion & $0,115^{\star *}$ & $0,008(1,275)$ & $0,002(0,350)$ & 0,6755 & 0,00021 & $-0,0001$ \\
\hline \multirow{2}{*}{$\begin{array}{l}\text { Intraday Results } \\
\text { (Session One) }\end{array}$} & $1 \%$ criterion & $0,1259^{* *}$ & $0,0027(0,1100)$ & $0,0717^{\star}(2,8706)$ & $4,1235^{\star}$ & 0,0032 & 0,0024 \\
\hline & $5 \%$ criterion & $0,1242^{\star *}$ & $0,0037(0,3249)$ & $0,0447^{\star \star}(4,000)$ & $7,9981^{\star *}$ & 0,0061 & 0,0054 \\
\hline \multirow{2}{*}{$\begin{array}{l}\text { Intraday Results } \\
\text { (Session Two) }\end{array}$} & $1 \%$ criterion & $0,1327^{\star \star}$ & $-0,0044(-0,1674)$ & $0,0305(1,1579)$ & 0,6863 & 0,0006 & $-0,0003$ \\
\hline & $5 \%$ criterion & $0,1323^{\star *}$ & $-0,0029(-0,2402)$ & $0,0147(1,2301)$ & 0,8031 & 0,0007 & $-0,0002$ \\
\hline \multicolumn{8}{|c|}{ t-statistic in parentheses } \\
\hline \multicolumn{8}{|c|}{ * Significance at $5 \%$} \\
\hline${ }^{* *}$ Significance at & & & & & & & \\
\hline
\end{tabular}

For session two market, the average levels of stock dispersions $(\alpha)$ are also positive and statistically significant under both $1 \%$ and $5 \%$ level. The results indicate that while the beta coefficients of the down markets $\left(\beta^{D}\right)$ are negative but statistically insignificant, the beta coefficients of the up markets $(\beta$ U) are positive but statistically insignificant under both $1 \%$ and $5 \%$ criteria. These estimates of $\beta^{D}$ and $\beta^{U}$ show the evidence against the presence of any herd behavior. In other words, large dispersions between stock returns and market return are observed during extreme up and down market movement days, contrary to expectation. Thus, it can be said that the stock returns do not diverge from session two market returns, implying no herding in up and down markets. Moreover, the estimates of session two market are smaller than the session one markets' estimates. This small dispersion indicates that even if there is no herding, stock returns diverges from the market return less in session two market, by contrast with session one market. Thus, it can be concluded that tendency of herd behavior is higher in session two markets. On the other hand, $F$ value is insignificant to explain goodness of the model. It means that the model is not valid for the sample of session two market. 
The methodology of the cross-sectional absolute valuation of the stocks (CSAD) was constructed as a deeper analysis to measure return dispersions. This analysis, suggested by Chang et al. (2000), facilitates the detection of herding over the entire distribution of market returns (Chiang, Li and Tan, 2010: 113). A non-linear relation is expected between the market return and stock returns in Borsa Istanbul, in the presence of herd behavior. The statistics reported in Table 2 indicate regression results on the basis of daily and intraday data. First of all, for the overall market, the constant variable $(\alpha)$ which indicates the average dispersion, is positive and statistically significant. Moreover, positive and significant coefficient of $\mathrm{y}_{1}$ indicates that the cross-sectional absolute valuation increases with an increase of absolute market return at the rate of 0.4674 . Negative and statistically significant coefficient of $\gamma_{2}$ is expected as an indicator of herd behavior. However, the coefficient $\mathrm{y}_{2}$ is positive. This result also shows a linear relation for the entire market. Thus, there is no evidence of non-linear relation, hence no herd behavior in Borsa Istanbul. The model explains the $39.7 \%$ of the dependent variables as given with the adjusted R-squared statistics. Moreover, according to the Fstatistics of the daily model, it is seen that the model is valid at $1 \%$ level. In both up and down markets, even if there is significant relationship between stock return dispersions and market return, positive $\mathrm{Y}_{2}$ coefficient of both markets indicates evidence against the presence of non-linearity. This implies that CSAD does not increase at a decreasing rate. In other words, CSAD increases when the market return increases. Thus, it can be concluded that there is no herd behavior in both up and down markets in Borsa Istanbul. Additionally, when comparing up and down market models, the rate of increase is 0.4603 in the up market, while it is 0.4791 in the down market, as reported in Table 3. This means that investors tend to herd more in up markets rather than down markets because of the smaller dispersion, consistent with the results of cross-sectional standard deviation of the stocks. As a result, when the regressions are conducted to analyze returns dispersions under market stress days, the estimated coefficients for $\gamma^{2}$ are positive indicating that there is no evidence of herd behavior for both up and down markets by using daily stock returns. Even if herding is not observed for both up and down markets, larger dispersion from the average market return indicates the probability of less herding for down markets, as similar with the result of Table 1 . The R-squared value shows that $35 \%$ and $41 \%$ of the variation in cross-sectional absolute valuations can be explained by daily market returns and squared term for both up and down markets, respectively. Furthermore, $F$ values of up and down market models are significant enough to indicate validity of the models.

The statistics reported in Table 2 are also based on the intraday data with the returns reported as session one and session two markets. For session one market, the equation of $C S A D_{t}=a+\gamma_{1}\left|R_{m, t}\right|+\gamma_{2}\left(R_{m, t}\right)^{2}$ shows the results. The constant variable $(a)$ is positive and statistically significant. Positive and significant coefficient of $\mathrm{\gamma}_{1}$ indicates that stock dispersions increase when absolute market return increases. Positive and statistically significant coefficient of $\gamma_{2}$ provides evidence of linearity. Thus, it can be said that stock returns diverge from the market return, hence indicating no herd behavior, as in crosssectional standard deviation method. When the market is up, the relation between 
cross-sectional absolute valuation and the squared market return $\left(\gamma_{2}\right)$ is positive and also significant at the level of $1 \%$ pointing to absence of herd behavior in session one

market. Similar with the up market, the coefficient of $\gamma_{2}$ for down market of session one is also positive and significant implying evidence against the herd behavior. Positive and significant coefficient of the absolute market return indicates a linear relationship between stock market returns and their dispersions during up and down extreme market movement days. Thus, it can be accepted that there is no herd behavior if the relation between market return and stock dispersion is linear during up and down market

\begin{tabular}{|c|c|c|c|c|c|c|}
\hline & A & $\gamma_{1}$ & $\gamma_{2}$ & $\mathrm{~F}$ & $\mathrm{R}^{2}$ & Adjusted $\mathrm{R}^{2}$ \\
\hline \multicolumn{7}{|c|}{ Regression Results for Daily Data } \\
\hline Entire market & $0,0236^{* *}$ & $0,4674^{* *}(1,313)$ & $4,8334^{\star \star}(8,004)$ & $2.114,2^{* *}$ & 0,3973 & 0,3971 \\
\hline Up markets & 0,0241 & $0,4603^{* *}(9,577)$ & $4,6476^{* *}(5,761)$ & $1.010,3^{* *}$ & 0,3839 & 0,3535 \\
\hline Down markets & $0,0229 * *$ & $0,4791^{\star *}(9,454)$ & $4,9616^{\star \star}(5,724)$ & $1.108,42^{* *}$ & 0,4138 & 0,4135 \\
\hline
\end{tabular}

Regression Results for Session One Market

\begin{tabular}{lcccccc} 
Entire market & $0,0233^{* *}$ & $0,5398^{* *}(9,8939)$ & $4,9776^{* *}(5,8586)$ & $5,8990^{* *}$ & 0,3142 & 0,3137 \\
Up markets & $0,0233^{* *}$ & $0,5378^{* *}(9,844)$ & $5,000^{* *}(5,535)$ & $589.01^{* *}$ & 0,3140 & 0,3134 \\
Down markets & $0,0260^{* *}$ & $0,5136^{* *}(4,1960)$ & $3,6735^{*}(2,4693)$ & $1,4747^{* *}$ & 0,4559 & 0,4528 \\
\hline
\end{tabular}

Regression Results for Session Two Market

$\begin{array}{lcccccc}\text { Entire market } & 0,0245^{* *} & 0,4904^{* *}(8,1588) & 5,2700^{* *}(4,7014) & 3,9540^{* *} & 0,2507 & 0,2501 \\ \text { Up markets } & 0,0245^{* *} & 0,4913^{* *}(8,1748) & 5,1958^{* *}(4,6282) & 3,893^{\star *} & 0,2479 & 0,2473 \\ \text { Down markets } & 0,0233^{* *} & 0,5565^{* *}(10,6397) & 4,014^{* *}(4,8785) & 398.87^{* *} & 0,2560 & 0,2554\end{array}$

t-statistic in parentheses

* Significance at $5 \%$

**Significance at $1 \%$

movement days in session one market. According to the adjusted R-squared statistics,

Table 2 Regression results for cross-sectional absolute valuation of the stock returns

the model explains the $31 \%$ of the dependent variable. Furthermore, the R-squared values are $31 \%$ for up market and $45 \%$ for down market. As seen, the down market model explains the variation in cross-sectional absolute valuations at a higher degree than up market model. The models are valid at $1 \%$ significance on the basis of $\mathrm{F}$ value.

For session two market, positive and significant coefficient of $\mathrm{\gamma}_{1}$ indicates that the crosssectional absolute valuation of the stock returns increases with an increase in the 
average market return at the rate of 0.4904 . Positive coefficient of $\mathrm{\gamma}_{2}$ is not an indication of non-linear relation between cross-sectional absolute valuation and the average market return. It suggests that cross-sectional absolute valuation does not increase at a decreasing rate when the average market return increases hence providing evidence against the herd behavior. The constant value $(a)$ is also positive and significant. Thus, it can be accepted that there is no herd behavior if the relation between market return and stock dispersion is linear in session two market. The adjusted R-squared value shows that $25 \%$ of cross- sectional absolute valuation can be explained by using intraday market return of session two. $F$ value is statistically significant at the $1 \%$ level, thus, the model is valid. Table 2 exhibits the regression results for up and down market models in session two market by using cross-sectional absolute valuation of the stock returns (CSAD). Similar with the market session one, positive value of $\gamma_{1}$ indicates that absolute market returns increase with CSAD. The relation between cross-sectional absolute valuation and the squared market return $\left(\mathrm{\gamma}_{2}\right)$ is also positive and significant suggesting the linearity and absence of herd behavior under the up and down market conditions. Thus, it can be supported that there is no herd behavior if the relation between market return and stock dispersion is linear during up and down market movement days in session two market. The adjusted R-squared values of two models are very close. $\mathrm{F}$ values of the models for up and down markets are significant enough to explain goodness of the model.

\section{Regression results for cross-sectional volatility of beta coefficients}

Cross-Sectional Volatility of Beta Coefficients suggested by Hwang and Salmon (2004) has also been employed to investigate herd behavior in Borsa Istanbul.

Table 3 provides the regression results for the equations of three state-space models on daily basis. Model 1 reported in Table 3 indicates exhibits findings of $\log \left[S t d_{c}\left(\beta_{i m t}^{b}\right)\right]=$ $\mu_{m}+H_{m t}+v_{m t}$. Model 2 includes market volatility and market return variables ( $\log \left[S t d_{c}\right.$ $\left.\left.\left(\beta_{i m t}^{b}\right)\right]=\mu_{m}+H_{m t}+c_{m 1} \log \sigma_{m t}+c_{m 2} r_{m t}+v_{m t}\right)$. The results of the equation of $\log$ [Std $\left.\left(\beta_{i m t}^{b}\right)\right]=\mu_{m}+H_{m t}+c_{m 1} \log \sigma_{m t}+c_{m 2} r_{m t}+c_{m 3} S M B_{t}+c_{m 4} H M L_{t}+v_{m t}$ are also reported as Model 3, in Table 3.

Model 1 indicates significant coefficient of $\sigma_{\mathrm{mn}}$, supporting the existence of herd behavior at a rate of $51 \%$ towards the market portfolio. According to the signal-proportion value ${ }^{2}$, herding also explains around $50 \%$ of the total variability in cross-sectional volatility of beta coefficients. $F$ value verifies the validity of the model at the $1 \%$ significance. Model 2 reports stronger evidence of herd behavior when the market volatility and the market return are taken into account. Hwang and Salmon (2004: 23) explain that significant coefficient of herding $\left(\sigma_{m n}\right)$ is not enough to indicate herd behavior, but the herding level can be examined given the state of the market. Thus, the herding coefficient of $\sigma_{m n}$ is expected to be close to 1 for the high levels of herding. For instance, if $\sigma_{m n}=1$, there is

\footnotetext{
2 Proportion of Signal value is calculated by dividing the $\sigma_{m n}$ by the time series standard deviation of the logarithmic cross-sectional standard deviation of the betas, which according to Hwang and Salmon (2004) indicates what proportion of the cross-sectional volatility of the betas is explained by herding (Gavriilidis et al., 2013: 19).
} 
perfect herding. In addition, when the market volatility and the market return are added to the model, the coefficient of herding is still significant. This result shows that the changes in the cross-sectional volatility of beta coefficients could be explained by intentional herding rather than changes in these fundamentals. In other words, investors do not herd because of publicly known changes in market fundamentals. Thus, it can be argued that they herd intentionally in Borsa Istanbul. It is also seen that when the

Table 3 Regression results for cross-sectional volatility of beta coefficients

\begin{tabular}{|c|c|c|c|c|c|c|c|}
\hline & $\sigma_{m n}$ & $c_{m 1}$ & $c_{m 2}$ & $c_{m 3}$ & $c_{m 4}$ & $\mathrm{~F}$ & $\begin{array}{l}\text { Proportion } \\
\text { of Signal }\end{array}$ \\
\hline \multicolumn{8}{|c|}{ Regression Results for Daily Data } \\
\hline Model 1 & $0,51111(101.3)^{\star \star}$ & - & - & - & - & $10261.15^{\star \star}$ & 0.5046 \\
\hline Model 2 & $0.6055(112.7)^{\star *}$ & $-0.5559(-32.3)^{* *}$ & $-0.0147(-2.3)^{\star}$ & - & - & $4491.65^{\star *}$ & 0.5373 \\
\hline Model 3 & $0.8651(198.0)^{\star *}$ & $-0.3250(-25.6)^{* *}$ & $0.0004(0.1)$ & $0.0269(7.9)^{\star \star}$ & $-0.0430(-17.6)^{* *}$ & $7976.04^{\star *}$ & 0.4369 \\
\hline \multicolumn{8}{|c|}{ Regression Results for Session One Market } \\
\hline Model 1 & $0.4794(86.7)^{\star \star}$ & - & - & - & - & $7519.584^{\star *}$ & 0.5529 \\
\hline Model 2 & $0.5576(93.4)^{\star *}$ & $-0.4315(-23.6)^{\star *}$ & $-0.0559(-8.3)^{\star *}$ & - & - & $3086.398^{* *}$ & 0.5970 \\
\hline Model 3 & $0.5570(91.7)^{\star *}$ & $-0.4171(-22.1)^{\star *}$ & $-0.0572(-8.4)^{\star *}$ & $0.0011(0.2)$ & $-0.0144(-3.8)^{\star \star}$ & $1791.689^{\star *}$ & 0.6074 \\
\hline \multicolumn{8}{|c|}{ Regression Results for Session Two Market } \\
\hline Model 1 & $0.8304(177.8)^{\star \star}$ & - & - & - & - & $31621.23^{\star *}$ & 0.4670 \\
\hline Model 2 & $0.8542(193.3)^{\star *}$ & $-0.3448(-26.6)^{\star *}$ & $0.0012(0.26)$ & - & - & $12528.21^{\star *}$ & 0.4419 \\
\hline Model 3 & $0.8651(198.0)^{\star *}$ & $-0.3250(-25.6)^{* *}$ & $0.0004(0.1)$ & $0.0269(7.9)^{* *}$ & $-0.0430(-17.6)^{* *}$ & $7976.04^{* *}$ & 0.4369 \\
\hline
\end{tabular}

t-Ratios in parentheses

* Significance at $5 \%$

${ }^{* *}$ Significance at $1 \%$

market return increases, the cross-sectional volatility of beta coefficients decreases, indicating higher tendency of herding in up markets. As presented in Model 3, size and value factors, which are derived from The Fama-French Factor Model, were added to the equation. The higher herding level $(86.51 \%)$ is found. The coefficient of $\sigma_{m n}$ is still significant indicating an intentional herding. There is a linear relationship between the size factor $(S M B)$ and the cross-sectional standard deviation of the betas. When the firm size increases, the cross-sectional standard deviation increases and thus, herding decreases. Negative and statistically significant coefficient of book-to-market ratio 
$(H M L)$ also indicates that it increases with decreases of the cross-sectional standard deviation, as expected. Because higher book-to-market value may be an indicator of smaller firm size. While firm size ( $S M L)$ decreases, herding increases, as stated earlier. $F$ values indicate that the models are valid at the level of $1 \%$. Total variability in crosssectional volatility of beta coefficients is explained by herding at a rate of $53.73 \%$ for model 2 and $43.69 \%$ for model 3 , as given with signal-proportion values.

Table 3 also reports the results based on intraday data of session one and session two market. According to coefficients of $\sigma_{m n}$, herd behavior is found for three of the models but the level of herding shows a minor difference in session one market. Thus, it can be said that there is herd behavior among investors in session one market. Additionally, when variables of market volatility, market return, size and value factors are included, there is still significant $\sigma_{m n}$, implying intentional herding rather spurious herding. Comparable with the results of Model 2 on daily basis, when the market volatility decreases, the cross-sectional standard deviation of beta coefficients increases. Model 3 reports the regression results under Fama-French Model as well as CAPM. However, while no significance is found for $S M L$ factor, negative and significant coefficient is found for HML factor. Non-linear relation shows that when HML factor increases, the crosssectional standard deviation of the betas decreases and herding increases. $F$ value verifies the validity of the three state-space models at the $1 \%$ significance. Signalproportion values indicates that the cross-sectional volatility of the beta coefficients is explained by herding at a rate of $55.29 \%, 59.70 \%$ and $60.74 \%$ for model 1 , mode 2 and model 3, respectively.

The results of three state-space models for session two market are also presented in Table 3. By contrast with the results of session one market, the table indicates the existence of herd behavior at a higher degree of above $80 \%$ for three of the models. This result is consistent with the result of cross-sectional dispersion of the stocks. Additionally, when market fundaments are taken into consideration, the significance of herding does not change. It can be said that there is an intentional herding in session two market in Borsa Istanbul. Moreover, when market volatility increases, the crosssectional standard deviation of beta coefficients decreases, as in the session one market. Additionally, insignificant coefficient of the market return shows that there is no relationship between the market return and the cross-sectional standard deviation of beta coefficients. SMB and $H M L$ coefficients are significant at $1 \%$ level. It can be concluded that herding is lower in firms which have higher sizes. Herding explains around $46.7 \%, 44.19 \%$ and $43.69 \%$ of the total variability in cross-sectional volatility of beta coefficients. The model is valid because of the significance of $F$ value at the $1 \%$ level.

\section{Conclusion}

In the traditional approach, efficient market hypothesis was widely accepted in finance literature. This hypothesis assumes that investors behave rationally and it is difficult to have abnormal returns. In the 1980s, researchers have focused on the investor 
psychology because of the unexpected market events which cannot be explained by traditional finance. In this behavioral approach, investors are assumed not to be fully rational and they are affected by their beliefs and emotions.

In this study, herd behavior is investigated in Borsa Istanbul by using daily and intraday stock returns. While the daily data covers the period from 1988 to 2014, intraday data starts from $2^{\text {nd }}$ January 1995 . Thus, the sample enables to compare both daily returns with the intraday returns and session one market returns with session two market returns. The data of the market return is collected from BIST 100 Index in Borsa Istanbul. There are 6417 daily observations and 9559 intraday observations for Borsa Istanbul. The sample size increases from 47 firms in 1988 to 441 firms in 2014.

Two different methodologies are used to detect herd behavior. The first methodology of cross-sectional standard deviation of stock returns aims to investigate return dispersions during extreme up and down market movement days. These days are captured by dummy variables and then regression analyses is conducted to test herd behavior. The results of regression analysis indicates that there is no herd behavior during extreme market movement days. Thus, the cross-sectional standard deviation of stock returns do not diverge from the overall market. However, even if there is no herding for up and down markets, lower coefficient of up markets indicates that stock returns diverge from the market index less and hence investors tend to herd more in up markets in contrast with down markets (Christie and Huang, 1995). When the model is analyzed by using the intraday data, the absence of herding is still valid for both session one and session two markets. This may be an indicator of rationality of investors in Borsa Istanbul. This rationality may provide investors to decide based on their own beliefs rather than following the others. While these results are consistent with the assumptions of efficient market hypothesis, they contradict with the assumptions of herd behavior. Extended cross-sectional absolute valuation model captures the non-linear relation between stock dispersions and market return. It is expected that if the relation is non-linear, there is herd behavior in Borsa Istanbul. However, a linear relation is found indicating the absence of herding. When compared the results of up and down market models, higher coefficients of down markets also support the view that stock returns deviate more from the overall market return and investors tend to herd less in down markets in comparison with the up markets.

The methodology based on the cross-sectional volatility of beta coefficients suggested by Hwang and Salmon (2004) is also used to detect herd behavior in Borsa Istanbul. Through this model, herding is expected to be observed under not only extreme but also normal market conditions. In the presence of herding, this model provides opportunity to determine whether herd behavior is intentional or not in Borsa Istanbul by using market volatility, market return, size and value factors. The results indicate that the higher herding level is reported in session two markets in contrast with the session one markets. Furthermore, the existence of intentional herding is found by using both daily and intraday intervals. 
This study is the first comprehensive attempt to measure herding in terms of market volatility, market return, size and book-to-market ratio factors in Borsa Istanbul and can be considered as one of the initial studies in the field of behavioral finance, to the best knowledge of the researcher. Furthermore, this is the first study that investigates herding covering such an extensive period (1988-2014) and compares daily and intraday stock returns to evaluate herd behavior in Borsa Istanbul.

Low volatility may be one of the reasons of herd behavior. Investors may prefer to follow the market trend when the market is not volatile in Borsa Istanbul. They do not trust other investors' decisions and decide based on their own beliefs during these uncertain and volatile market conditions, as Hwang and Salmon (2004) argued. This can explain why investors tend to herd more in session two markets in contrast with session one markets. Researchers state that session one market is more volatile and this higher volatility causes investors to avoid herding. During the day, the market becomes stable. The stability of session two market induces investors to herd more because of their confidence about the future direction of the market (Stoll and Whaley, 1990; Madhavan, Richardson and Roomans, 1997; Guner and Onder, 2002). The effect of volatility can also be argued for up and down markets. As stated earlier, the tendency of herding among investors is more in up markets than down markets in Borsa Istanbul. Increased volatility and uncertainty in down markets may decrease the possibility of herding, consistent with arguments of the study of Hwang and Salmon (2004). In contrast, positive values in up markets give confidence to investors about the future performance of the market. Thus, they follow the market trend more in up markets. As a result, the volatility would be higher when the investors are less confident about their evaluation of the market, and would be lower when the investors are more confident, and thereby herding is a distorting phenomenon to the market efficiency.

The results of the study also show that herd behavior is observed more on the stocks with small capitalization in Borsa Istanbul. Bikhchandani and Sharma (2000) state that investors avoid risk for small size firms because of the difficulty of gathering information about them.

Herding can also be explained by information acquisition during market stress days in Borsa Istanbul. Wang (2008) states that gathering information is difficult and expensive in developing markets, instead, observing and imitating other investors' decision or the market index is relatively cheap and easy. Thus, investors tend to follow the market trend in Borsa Istanbul which is a developing market.

Moreover, institutional investors herd more than individual investors, because they are able to reach more information about other investors and they affect stock market returns more than individual investors do. In line with this argument, it can be said that there may be sufficient institutional investors to affect stock prices in Borsa Istanbul. Market makers, which are mostly institutional investors, may manipulate stock prices and may lead markets to inefficiency. Because they may direct investors to their benefits. Investors may also herd based on the correlated information signals of 
financial analysts who forecast earnings and make recommendations for investors. Because of the economic and political instability in Borsa Istanbul, newsletters or other media instruments may also be followed by investors, especially who do not collect information easily. Researchers also argue that domestic investors follow the foreign investors. This may be valid in Borsa Istanbul because it is found that there is an intentional herding among investors.

There are three limitations of this study. Firstly, macroeconomic variables could not be added to the model. Because daily data of these variables is not available in the website of Central Bank of Turkey. The other limitation of the study is that the direction of herding could not be measured. There are two reasons. Firstly, it is not possible to find it by using the methodologies based on the cross-sectional dispersion of the stocks and the cross-sectional volatility of the betas. The other reason is that there is no clear distinction of investor types in the website of Borsa Istanbul. Because, it is not possible to determine which investors are institutional and which are not, and thus, it could not be reached clearly whether the individual investors follow the institutional investors or not. The third limitation is that the existence of herding among foreign investors cannot be tested in Borsa Istanbul by using stock returns. Because stock returns of foreign investors cannot be obtained from the website of Borsa Istanbul.

For further studies, it would be suggested to incorporate macroeconomic variables to evaluate herd behavior among investors. This provides a more comprehensive analysis to evaluate changes in herding levels in Borsa Istanbul. This study does not take into account herd behavior towards these variables. Moreover, Lakonishok, Shleifer and Vishny (LSV) Measure can be used to test the existence of herding in further studies. It would provide to determine the direction of herd behavior. Although there is no distinction between institutional and individual investors, breakdown of monthly traded values of customer, fund and portfolios are reported in Borsa Istanbul. Daily breakdowns of them can also be requested from Borsa Istanbul. Furthermore, the direction of herding between domestic and foreign investors can be investigated based on their traded values in Borsa Istanbul. As stated earlier, it is found that investors tend to herd less during market stress days in Borsa Istanbul. Up and down markets and session one and session two markets are compared in this study to evaluate herding under risky market conditions. Consistently, Hwang and Salmon (2004) state that the crisis has contributed to a reduction in herding and is clearly identified as a turning point in herd behavior. Therefore, crisis periods can be determined and taken into consideration as sub-periods to test the effect of crisis on herding behavior among investors in Borsa Istanbul. At last, it is predicted that marker makers may have a great effect on investors in Borsa Istanbul. For a further research, market makers, which are listed on the website of Borsa Istanbul, can be separated from the other investors and then it can be investigated whether investors follow market makers or not. Furthermore, to test the effect of market makers, analysis can be conducted to each sector. The different herding levels at the sectors can provide information on which sectors herding is more valid in different periods and whether there is an effect or direction of market makers on this herding activity or not. 
Overall, observed intentional herding may provide an evidence of inefficiency in Borsa Istanbul. Therefore, short-term imbalances and mispricing may occur. With economic and political instability in addition to this mispricing, to reach correct information becomes more difficult and expensive. To exploit this mispricing which occurs due to herding, an important implication for investors is to invest in stocks for a long term unlike short-term structure of herding and to avoid quick reactions to economic fluctuations. In addition, one of the reasons of intentional herding is compensation of managers, as stated earlier. This leads them to behave irrationally. If these compensations are designed better for managers, this makes institutions more transparent. Mispricing is prevented and prices can be close to their fundamental values in the existence of transparency. To exploit this mispricing and gather information easily, one implication can be suggested for policy makers. New regulations may be employed for market makers to prevent large price movements which may occur as a result of short term price imbalances in stocks. Because their direction to investors and their press releases may cause the manipulation of the market and thus herding may arise.

\section{Acknowledgements}

I am grateful to my supervisor Banu Durukan for her valuable guidance and constant encouragement during the completion of this research.

\section{References}

Altay, E. (2008). Sermaye Piyasasında Sürü Davranışı: IMKB'de Piyasa Yönünde Sürü Davranışının Analizi. BDDK Bankacılık ve Finansal Piyasalar. 2(1): 27-58.

Al-Shboul, M. (2012). Asymmetric Effects and the Herd Behavior in the Australian Equity Market. International Journal of Business and Management. 7(7): 121-140.

Bikhchandani, S. and Sharma, S. (2000): Herd Behavior in Financial Markets: A Review. IMF Working Paper. 1-32.

Cajueiro, D. and Tabak, B.M. (2009). Multifractality and Herding Behavior in the Japanese Stock Market. Chaos, Solitons and Fractals. 40(1): 497-504.

Caparrelli, F., D'Arcangelis A.M. and Cassuto, A. (2004). Herding in the Italian Stock Market: A Case of Behavioral Finance. Journal of Behavioral Finance. 5(4): 222-230.

Chang, E.C., Cheng, J.W. and Khorana, A. (2000). An Examination of Herd Behavior in Equity Markets: An International Perspective. Journal of Banking and Finance. 24(10): 1651-1679.

Chen, G., Rui, O.M. and Xu, Y. (2003). When Will Investors Herd: Evidence from the Chinese Stock Markets. Working Paper, University of Texas, Dallas.

Chiang, T.C., Li, J. and Tan, L. (2010). Empirical Investigation of Herding Behavior in Chinese Stock Markets: Evidence from Quantile Regression Analysis. Global Finance Journal. 21(1): 111-124.

Chiang, T.C., Li, J., Tan, L. and Nelling, E. (2011). Dynamic Herding Behavior in Pacific-Basin Markets: Evidence and Implications. 3rd EMG Conference on Emerging Markets Finance. Organized by Cass Business School, City University London. 5- 6 $6^{\text {th }}$ May 2011. 
Chiang, T.C. and Zheng, D. (2010). An Empirical Analysis of Herd Behavior in Global Stock Markets. Journal of Banking \& Finance. 34(8): 1911-1921.

Christie, W.G. and Huang, R.D. (1995). Following the Pied Piper: Do Individual Returns Herd around the Market. Financial Analysts Journal. 51(4): 31-37.

Coban, A.T. (2009). IMKB'de Sürü Davranışının Test Edilmesi. (Unpublished Master Thesis). Adana: Cukurova University.

Demirer, R. and Kutan A.M. (2006). Does herding behavior exist in Chinese Stock Markets. Journal of International Financial Markets, Institutions \& Money. 16(2): 123-142.

Demirer, R., Kutan, A.M. and Chen, C.D. (2010). Do Investors Herd in Energing Stock Markets?: Evidence from the Taiwanese Market. Journal of Economic Behavior and Organization. 76(2): 283295.

Dogukanlı, H. and Ergun, B. (2011). İMKB'de Sürü Davranışı: Yatay Kesit Değişkenlik Temelinde Bir Araştırma. Dokuz Eylül Üniversitesi İşletme Fakültesi Dergisi. 12(2): 227-242.

Economou, F., Kostakis, A. and Philippas, N. (2010). An Examination of Herd Behavior in Four Mediterranean Stock Markets. $9^{\text {th }}$ European Economics and Finance Society Conference Paper, Organized by the UADPhilEcon and the Department of Economics of the University of Athens. Greece. 3 - 6 th June 2010.

Fama, E.F. (1965). Random Walks in Stock Market Prices. Financial Analysts Jurnal. 21(5): 55-59.

Fama, E. F. and French, K. R. (1993). Common Risk Factors in the Returns on Stocks and Bonds. Journal of Financial Economics. 33(1): 3-56.

Gavriilidis, C., Kallinterakis, V. and Micciullo, P. (2007). The Argentine Crisis: A Case for Herd Behaviour? Working Paper. 1-30.

Gleason, K.C., Lee, C.I. And Mathur, I. (2003). Herding Behavior in European Futures Markets. Finance Letters. 1(1): 5-8.

Gleason, K.C., Mathur, I. and Peterson, M.A. (2004). Analysis of Intraday Herding Behavior Among the Sector ETFs. Journal of Empirical Finance. 11(5): 681-694.

Guner, N. and Onder, Z. (2002). Information and Volatility: Evidence from An Emerging Market. Emerging Markets Finance and Trade. 36 (6): 26-46.

Hassairi, S.A. and Viviani, J.L. (2011). Herd Behavior and Market Stress: The Case of Four European Countries. International Business Research. 4(3): 53-67.

Henker, J., Henker T. and Mitsios, A. (2006). Do Investors Herd Intraday in Australian Equities. International Journal of Managerial Finance. 2(3): 196-219.

Hwang, S. and Salmon, M. (2004). Market Stress and Herding. Journal of Empirical Finance. 11(4): 585616.

Javed, T., Zafar, N. and Hafeez, B. (2013). Herding Behavior in Karachi Stock Exchange. International Journal of Management Sciences and Business Research. 2(2): 19-28.

Kapusuzoglu, A. (2011). Herding in the Istanbul Stock Excahneg (ISE): A Case of Behavioral Finance. African Journal of Business Management. 5(27): 11210-11218. 
Kayalıdere, K. (2012). Hisse Senedi Piyasasında Sürü Davranışı: IMKB'de Ampirik Bir İnceleme. İşletme Araştırmaları Dergisi. 4(4): 77-94.

Lakonishok, J. Shleifer, A. and Vishny, R.W. (1992). The Impact of Institutional Trading On Stock Prices. Journal of Financial Economics. 32(1): 23-43.

Lao, P. and Singh, H. (2011). Herding Behavior in the Chinese and Indian Stock Markets. Journal of Asian Economics. 22(6): 495-506.

Liu, X. (2012). Essays on Corporate Finance and Financial Markets. (Unpublished Doctoral Dissertation). China: The Chinese University of Hong Kong.

Madhavan, A., Richardson, M. and Roomans, M. (1997). Why Do Security Prices Change? A Transaction-Level Analysis of NYSE Stocks. Review of Financial Studies. 10(4): 1035-1064.

Messis, P., Zapranis, A. and Kollias, C. (2014). Herding towards Higher Moment CAPM, Contagion of Herding and Macroeconomic Shocks: Evidence from Five Major Developed Markets. Journal of Behavioral and Experimental Finance. 4(4): 1-13.

Mobarek, A. and Mollah, S. (2013). Cross-Country Analysis of Herd Behavior in Europe: Evidence from Continental, Nordic and the PIIGS Countries. Behavioural Finance Working Group Conference Paper, Organized by Queen Mary University of London. 16 - 17th December 2013.

Pop, R.E. (2012). Herd Behavior Towards The Market Index: Evidence From Romanian Stock Exhange. Munich Personel RePEc Archive. 51595(26).

Seetharam, Y. and Britten, J. (2013). An Analysis of Herding Behavior during Market Cycles in South Africa. Journal of Economics and Behavioral Studies. 5(2): 89-98.

Schwert, G.W. (1989). Why Does Stock Market Volatility Change Over Time? The Journal of Finance. 44(5): 1115-1153.

Stoll, H.R. and Whaley, R.E. (1990). The Dynamics of Stock Index and Stock Index Futures Returns. The Journal of Financial and Quantitative Analysis. 25(4): 441-468.

Tan, L. (2005). Empirical Analysis of Chinese Stock Market Behavior: Evidence from Dynamic Correlations, Herding Behavior, and Speed of Adjustment. (Unpublished Doctoral Dissertation). Philadelphia: Drexel University.

Tan, L., Chiang, T.C., Mason, .R. and Nelling, E. (2008). Herding Behavior in Chinese Stock Markets: An Examination of $A$ and B Shares. Pacific-Basin Finance Journal. 16(1): 61-77.

Wang (2008). Herd Behavior towards the Market Index: Evidence from 21 Financial Markets. IESE Business School Working Paper. 776.

Zheng, D. (2010). Two Essays on Financial Market Behavior: Evidence from International Markets. (Unpublished Doctoral Dissertation). Philadelphia: Drexel University. 